\title{
Some reflections on Chomsky's notion of reference
}

\author{
Enrico Cipriani \\ University of Torino, Italy
}

\begin{abstract}
In this paper, I will focus on Chomsky's interpretation of the notion of reference. I will summarize Chomsky's criticisms against the externalist interpretation of such notion, and I will then focus on the internalist (and syntactic) interpretation that the MIT linguist provides. Then I will focus on the relation between the internalist interpretation and the notion of truth, discussing in particular Casalegno and Hinzen's objections: I will point out that truth does not represent a particular problem for the internalized reference. Finally, I will show how Chomsky explains, inside the internalist perspective, the phenomenon of communication. In Conclusions, I will sketch two important points.
\end{abstract}

Keywords: internalized reference, internalist vs. subjective truth, communication, reference vs. referential acts, constitutional uniformity of speakers, I-language, truth conditions

\section{Introduction}

The notion of reference is relevant in Chomsky's thought for at least three reasons: because it represents a topic of debate between the MIT linguist and many scholars; because it is the crucial notion of Binding Theory (BT, Chomsky 1981), especially in the Minimalist Program (see Chomsky 1995: 211); and because Chomsky has provided an internalist interpretation of this notion.

Since the Seventies, Chomsky has often judged the notion of reference interpreted as a hypothetical relation between expressions and objects as a non-scientific notion, which has no place in the scientific discourse (while it has in the philosophical debate). This position was expressed by Chomsky to answer against those scholars who sustained that his, of Chomsky, use of the notion of logical form was inadequate, since it did not involve the notion of reference. In fact, the logical form (which should be written as "Logical Form", to point out that we are dealing with a technical notion of generative grammar) used by Chomsky describes only those semantic aspects which are determined by the syntactic structure of the sentence (like quantifier raising, scope relations, etc.), ignoring many other semantic contents which are usually expressed by the logical form used in the philosophical tradition, since Frege to Williamson. To stress the distinction between the traditional logical form and the 
notion used in generative grammar, in a first time Chomsky used the notion of syntax of logical form (see Rizzi 1978: 168), while then he introduced the (technical) notion of Logical Form. In the same time, however, he defended his criticism against the notion of reference, that I have just mentioned.

The notion of reference is the crucial notion of BT. As it is well-known, BT is an attempt to describe the universal restrictions to the coreferential relations between the syntactic constituents of a hierarchical syntactic tree (see Chomsky 1981, Reuland 2001). Actually, in a first time the notion privileged by Chomsky was that of index (see i.e. Chomsky 1981: 6): BT explained when two or more constituents can be coindexed, and when they cannot. However, since the Minimalist Program, the notion of index has been replaced by the notion of reference (see i.e. Chomsky 1995: 211), and BT has been formulated focusing on the probegoal relation between syntactic constituents (see i.e. Chomsky 2007, 2008). Since the Eighties (see i.e. Chomsky 1986: 44-45), Chomsky has interpreted the notion of reference used in BT as a syntactic notion, which could be conceived as a relation between expressions and internal entities of some (unspecified) cognitive domain (see i.e. Chomsky 2000: 37-39). Chomsky assumes, in other words, that the notion of reference can be interpreted only as an internal notion, and every theory of reference which supports a hypothetical relation between words and external objects must be rejected (so, both the Fregean theory and the Direct Reference Theory). Furthermore, Chomsky explicitly points out that it would be perverse to try to find a relation between the internal (mental) entities and the external objects in the world.

Some scholars (see i.e. Casalegno 1997, Hinzen 2002) pointed out that Chomsky's internalized reference does not permit to understand how communication is possible. Let's summarize the problem this way: if the reference is an individual and internal relation, how do speakers converge in their truth judgments and in their use of language? In other words: how do speaker can successfully communicate? Chomsky (2000) briefly focuses on communication: I will try to reconstruct his argument and to stress its relation with Davidson's theory of language.

\section{Chomsky's criticism against the notion of reference}

The notion of reference interested Chomsky since Syntactic Structures, where the MIT linguist supports the idea that the notion of meaning can be reduced to the notion of reference:

'To understand a sentence we must know much more than the analysis of this sentence on each linguistic level. We must also know the reference and meaning of the morphemes or words of which it is composed; naturally, grammar cannot be expected to be of much help here. These notions form the subject matter for semantics.' (103-104)

'Goodman has argued - to my mind, quite convincingly - that the notion of meaning of words can at least in part be reduced to that of reference of expressions containing these words.' $(103, \mathrm{n} .10)$

In particular, Chomsky thinks that a theory of meaning could be constructed on the notion of reference, as Goodman $(1943,1954)$ suggested: 
'Goodman's approach amounts to reformulating a part of the theory of meaning in the much clearer terms of the theory of reference, just as much of our discussion can be understood as suggesting a reformulation of parts of the theory of meaning that deal with so-called "structural meaning" in terms of the completely nonsemantic theory of grammatical structure. Part of the difficulty with the theory of meaning is that "meaning" tends to be used as a catch-all term to include every aspect of language that we know very little about. Insofar as this is correct, we can expect various aspects of this theory to be claimed by other approaches to language in the course of their development.' (104)

Chomsky tells us that a semantic theory based on the notion of reference would allow a reformulation of the "structural meaning" in non-semantic terms. By "structural meaning", Chomsky means those semantic aspects determined by the syntactic structure: for example, to explain the meaning of to hit, we must consider such notions as subject and object, which are grammatical (syntactic) notions; consequently, "the syntactic devices available in the language are being used fairly systematically" (Chomsky 1957: 104). The problem, when we deal with the structural meaning, is that "to assign 'structural meanings' to grammatical categories or constructions just as 'lexical meanings' are assigned to words or morphemes, is a step of very questionable validity" (104). Chomsky's thought can be summarized this way: we cannot deny that the grammatical structure contributes in determining the (structural) meaning; however, we do not dispose of any theory which explains the meaning of the single syntactic constituents of a sentence. This is evident, Chomsky says, if one considers that the notion of meaning is used to refer to several aspects which instead should remain separate. To sustain that it is impossible to establish the meaning of the single lexical items, Chomsky proposes the following argumentation. If $P$ is a lexical entry, we can adopt two hypothesis: we can suppose that the meaning of $P$ is fix, so that in every occurrence $P$ maintains its meaning; or we can assume that every occurrence of $P$ has a different meaning, even if the difference in the meaning is only partial. In this latter case, Chomsky says, we should explain how two occurrences (two identical phonetic expressions) have the same meaning; to do so, however, we should dispose of a rigorous method to measure the degree of convergence of two meanings, a method that we do not have. In the former case, instead, we should assume that the constant meaning of $P$ can be expressed by a fixed set of words, combined among them; but this way we would fall in the circularity (Chomsky 1957: 97-98). In fact, the meaning of $P$ would consist in the combination of a specific set of other lexical items $P_{1}, \ldots, P_{\mathrm{n}}$, which should be further decomposed, etc. One must remind that Chomsky is not mentioning the Quinean argument against the analytic-syntetic distinction or the componential analysis of concepts and meaning. This analysis, in fact, would have been formulated in the Sixties by Katz and Fodor (1963, see also Katz 1972), and would have been immediately hardly criticized (see i.e. Weinreich 1966). Quine's radical interpretation argument, instead, even if very influential in the philosophical debate, is not relevant for Chomsky, who has always criticized it. According to Chomsky, the analysis of our linguistic intuitions let us understand that there is "a rather clear distinction between truths of meaning and truths of fact", a distinction determined by the "a priori framework of human thought" which "provides necessary connections among concepts, reflected in connections of meaning, among words and, more broadly, among expressions involving these words". Quine's conclusion, in fact, 
'has been supported by reflection on an artificially narrow class of examples; among them concepts that have little or no relational structure. [...] When we turn to concepts with an inherent relational structure such as persuade or chase, or to more complex syntactic constructions such as those exhibiting referential dependence or causative and relative constructions, then it seems that semantic connections are readily discerned.'

(Chomsky 2000: 63-64)

After Syntactic Structures, Chomsky's faith in a theory of reference rapidly disappeared. Since the Seventies, in fact, Chomsky has rejected the externalist(s) interpretation(s) of reference: according to Chomsky, to postulate a relation between words and the world is not scientific; is a "kind of neo-scholastic picture" (Chomsky 2012: 28). Chomsky (2000) devotes many reflections to the criticism against the notion of reference. I quote one:

'A good part of contemporary philosophy of language is concerned with analyzing alleged relations between expressions and things, often exploring our intuitions about the technical notions "denote", "refer to", "true of", etc. said to hold between expressions and something else. But there can be no intuitions about these notions, just as there can be none about "angular velocity" or "protein". [...] it is not at all clear that the theory of natural language and its use involves relations of "denotation", "true of", etc. in anything like the sense of the technical theory of meaning.'

(Chomsky 2000: 130)

Chomsky's thought can be summarized this way: the notion of reference is not a common sense or a scientific notion; it is a pseudo-scientific notion, which cannot enter in the theoretical apparatus of the naturalistic analysis (see Casalegno 1997: 356).

The externalized notion of reference, instead, can be part of the analysis of artificial languages. Chomsky thinks that the notion of Bedeutung is adequate for the scientific languages. In these languages, in fact, we can construct symbolic objects which "may well aim towards the Fregean ideal", since they have "a semantics, based on the technical notion of Bedeutung, a relation between symbols and things" (Chomsky 2000: 131). This is not possible, instead, in natural language, where

'There are complex conditions - poorly understood, though illustrative examples are not hard to find - that an entity must satisfy to qualify as a "naturally nameable" thing: these conditions include spatiotemporaly contiguity, Gestalt qualities, functions within the space of human actions [...] A collection of leaves on a tree, for example, is not a nameable thing, but it would fall within this category if a new art form of "leaf arrangement" was devised and some artist had composed the collection of leaves as a work of art. He could then stipulate that his creation was to be named serenity. Thus it seems that there is an essential reference even to willful acts, in determining what is a nameable thing.'

(Chomsky 1975: 43-44)

and where

'Even the status of (nameable) thing, perhaps the most elementary concept we have, depends crucially on such intricate matters as acts of human will, again something understood without relevant experience, determined by intrinsic properties of the language faculty and others. A collection of sticks in the ground could be a (discontinuous) thing - say, a picket fence, a barrier, a work of art. But the same sticks in the ground are not a thing if left there by a forest fire.'

(Chomsky 2000: 127) 
Briefly, according to Chomsky, relata do not exist (see Voltolini 2001).

To sustain his criticism against the notion of reference, Chomsky has proposed some examples which appear frequently in his works: if one thinks to the names London, journal or book, Chomsky says, one must recognize that these words can be used to denote different things:

'Such notions as desk or book or house, let alone more "abstract" ones, are not appropriate for naturalistic inquiry. Whether something is properly described as a desk, rather than a table or a hard bed, depends on its designer's intentions and the ways we and others (intend to) use it, among other factors. Books are concrete objects. We can refer to them as such ("the book weighs five pounds"), or from an abstract perspective ("who wrote the book?"; "he wrote the book in his head, but then forgot about it"); or from both perspective simultaneously ("the book he wrote weighed five pounds"; "the book he is writing will weigh five pounds if it is ever published"). If I say "the deck of cards, which is missing a Queen, is too worn to use", that deck of cards is simultaneously taken to be a defective set and a strange sort of scattered "concrete object," surely not a mereological sum. The term house is used to refer to concrete objects, but from the standpoint of special human interest and goals and with curious properties. A house can be destroyed and rebuilt, like a city; London could be completely destroyed and rebuilt up the Thames in 1,000 years and still be London, under some circumstances. It is hard to imagine how these could be fit concepts for theoretical study of things, events, and processes in the natural world. Uncontroversially, the same is true of matter, motion, energy, work, liquid, and other common-sense notions that are abandoned as naturalistic inquiry proceeds [...]'

(Chomsky 2000: 20-21)

It can be noticed that in these examples Chomsky does not distinguish between common names and proper names. The philosophical tradition, since Mill to Kripke and Putnam, shows that while common names denote their relata in virtue of some properties of them, proper names directly denote specific objects: the meaning of proper names is their referent (see i.e. Putnam 1975, 1992, Kripke 1972, 1980). Chomsky seems to radicalize this conclusion, and extend it to common names too: according to Chomsky, not only proper names but also common names are not adequate for the distinction between Sinn and Bedeutung. Let's notice, however, that this conclusion is not fully satisfactory: in fact, even if it is hard to establish how book, journal, etc. denote their references, in the same time one must recognize that they do not denote radically different entities; perhaps, they denote different aspects of the same content (the "concrete" aspect of a book, and the "abstract" one: notice, furthermore, that we usually have only the "abstract"-"concrete" couterposition).

The pars construens of Chomsky's theory concerning reference consists in two hypothesis: the idea that the relation of reference is a syntactic and internal notion (see the next section) and the idea that speakers, not words, refer to objects in the world (see Delfitto and Graffi 2005: 19). As Chomsky (2000: 42) says, "there seems to be little reason to that a" notion of reference - intended as a relation between words and the world - "can be given a coherent and useful formulation as a relation holding between expressions and some kind of things, divorced from particular conditions and circumstances of referring. If it is so, there will also be no reasonable inquiry into a notion of "sense" or "content" that 'fixes reference' $(R)$, at least for natural language". The linguistic behavior of speakers is the topic of psycholinguistics, cognitive science, and other disciplines, and we cannot expect to study it by mental experiments. Concerning Putnam's Twin Earth experiment, for example, Chomsky says that 
'In one version [of Putnam's experiment], we are to explore our intuitions about the extension or reference of the word "water" on Twin Earth, where speakers identical to us use it to refer to XYZ, which is not $\mathrm{H}_{2} \mathrm{O}$. But we can have no intuitions about the question, because the terms extension, reference, true of, denote, and others related to them are technical innovations, which mean exactly what their inventors tell us they mean: it would make as little sense to explore our intuitions about tensors or undecidability, in the technical sense.'

(Chomsky 2000: 148)

This kind of experiments is useless in the naturalist inquiry, and does not help the formulation of technical notion of reference, truth, sameness, etc.: "with its questionable invocation of natural sciences, [in Putnam's experiment] we find that whether something is water depends on special human interests and concerns, again in ways understood without relevant experience" (Chomsky 2000: 128).

\section{The internalized reference}

The notion of reference is the crucial notion of BT (see Chomsky 1981, Reuland 2001). In the Eighties, Chomsky did not always use the notion of reference, but more often he talked about co-indexicalization; however, since the Minimalist Program (see in particular Chomsky 1995: 211, but also 2007 and 2008), Chomsky has explained the binding relation in terms of coreference. This notion has been interpreted by Chomsky as a syntactic notion, which could be defined as a "relation $R$ (read "refer") that is postulated to hold between linguistic expressions and something else, entities drawn from some stipulated domain $D$ (perhaps semantic values). The relation $R$, for example, holds between the expressions London (house, etc.) and entities of $D$ that are assumed to have some relation to what people refer to when they use the words London (house, etc.), though that presumed relation remains obscure". The MIT linguist does not shed light on the ontology of such entities, but he argues that "it would be perverse to seek a relation between entities in D and things in the world - real, imagined, or whatever - at least, one of any generality" (Chomsky 2000: 39).

Chomsky does not explain what entities are, but we can suppose that they correspond to concepts or to representations. On my opinion, the former hypothesis is the most plausible; however, if it was, it would not be clear why "it would be perverse to seek a relation between" such entities and the things in the world: concepts, if they exist, are involved in denotation. The latter hypothesis requires instead a clarification about the notion of representation. Chomsky (2000: 170) writes that

\footnotetext{
'The internalist study of language also speaks of "representations" of various kinds, including phonetic and semantic representations at the "interface" with other systems. But [...] we need not wonder what is represented, seeking some objectives constructions from sounds or things. The representations are postulated mental entities, to be understood in the manner of mental image of a rotating cube, whether it is the consequence of tachistoscopic presentations or a real rotating cube, or simulation at the retina in some other way; or imaged, for that manner.'
}

Following this quotation, representations correspond to mental entities, so that also the latter hypothesis seems plausible. Furthermore, let's consider that Chomsky, as in the case of concepts, argues that (a) there are innate semantic representations and (b) such 
representations are created by the combination of primitive elements (see Chomsky 2000: 184-189, where he answers to Putnam 1986a, b). In the interview with James McGilvray, Chomsky explicitly states that

'the term "representation" is used in a kind of technical sense in the philosophical literature which I think basically comes back to the theory of ideas. You know there's something out there and the impression of it becomes and idea, and then there's a relation - so, say, in Jerry Fodor's representational theory of mind there's a causal relation between the cat over there and the concept cat in your language of thought. And Kripke, Putnam, Burge have a picture roughly like that.

[...] There is some causal relation, and then, yes, it sets up the semantic relation of reference. And there is a factual question as to whether any of that happens. Obviously, there's some causal relation between what's outside in the world and what's in our head. But it does not follow that there's a symbol-object relationship [something like the reverse of causal one]

[...] If you look at the literature on cognitive science and neurology and so on and so forth, people are constantly talking about internal representations. But they don't mean that there's a connection between what's inside and some mind-independent entity. The term "internal representation" just means that something's inside.' (31-32) (my emphasis)

The problem in this words is that the notion of representation and that of concept seem to be complementary, while they cannot be, as Descartes explained with his chiliagon. The distinction between concepts and representation is even more clear if we consider that no representation is associated to many concepts (let's think i.e. to the concepts kilogram, weight, execration, etc.; for a different proposal, see Prinz 2002), that we can however use. Furthermore, it is not easy to sustain that concepts like execration, kilogram or weight are acquired - are learned - by a causal relation between the mind and the outside world (even if some scholars support this idea: see i.e. Borghi 2009 and Borghi and Cimatti 2009, 2010); perhaps, if we respect Chomsky's innateness theory of concepts (see Chomsky 2000 and Piattelli-Palmarini 1986), we can assume that concepts emerge (like syntactic structures do) in the speakers. That the concept and the representation are two different things is even more clear if we consider that a Fodorian causal relation between concepts and objects entails the impossibility of error in recognition an denotation, contrarily to what empirical studies show: ${ }^{1}$ as Putnam (1981: 19) pointed out, "one could possess any system of images you please and not possess the ability to use the sentence in situationally appropriate ways" (let's consider, furthermore, that there are many theoretical objections against Fodor's causal relation ${ }^{2}$.

1 As Marconi (1997) explains, naming is a two steps processing, which consists in the recognition and in the recovery of the name. It is possible that only one of these steps is jointed, while the other fails, as it happens in the case of some brain-damaged patients who are able to recognize the objects but not to name them (see i.e. Warrington 1985: 341-342, Riddoch and Humphreys 1987: 132 and Shallice 1988: 292 and ff.), or vice versa (see i.e. Kay e Ellis 1987, Miceli, Giustolisi e Caramazza 1991, Hart e Gordon 1992).

2 As Marconi (1997: 102-104) rightly points out, Fodor's explanation of Twin Earth experiment (see Fodor 1987, 1990) does not show that the causal relation of reference (the "aboutness") can be expressed in "nonsemantic and nonintentional terms" (Fodor 1987: 98); instead, it strongly involves the notion of intention, since "intending to refer to local samples is not a purely causal connection between a speaker and such samples". Furthermore, the notion of asymmetry dependency that Fodor proposes to explain the case where Twin Earthians name water both $\mathrm{XYZ}$ - which is the water on their planet - and $\mathrm{H} 2 \mathrm{O}$ does not respect Fodor's 
A further criticism concerns the notion of representation as used by Chomsky. This notion seems to have, for Chomsky, three different meanings: it can denote the phonetic and semantic representations that are mapped to the sensory-motor and conceptual-intentional systems (see Chomsky 2000, 2007, 2008); it can denote the syntactic representation (the Xbar) (see Chomsky 1995); or it can denote the traditional - and more ingenuous - notion of representation, like the "mental image of a rotating cube" (see Chomsky 2000: 170 just mentioned). However, while the first and the second interpretation of representation are plausible - they are technical notion of generative grammar - the third one lacks plausibility: even if it has been adopted for a time in Artificial Intelligence (see i.e. Rosenfeld 1988, Tye 1991, Meini and Paternoster 1996), the hypothesis that the representation associated to a concept is an image "stored" in our mind meets many criticisms: for example,

'Images are things, not rules. Thus they cannot connect anything to anything else (in particular, they cannot connect themselves to the output of perception or compare themselves to other images or generate other images with themselves as a pattern). On the other hand, as they are things, images are particular things (there are no other kinds of things). Consequently, they are different (in some respect) from most other images of the same kind or "falling under the same concept." Therefore, if to "fit" something else, in particular, another image, it is required that an image be exactly like it, then no image can fit most other images of the same kind. Of these two difficulties, the former is more basic, for, to repeat, even if an image were exactly like another (in some relevant sense), still a method of comparison would be needed by way of which it could be found to be exactly like it.'

(Marconi 1997: 177)

These reflections allow to stress two points. From a historical point of view, one can notice that Chomsky's thought concerning a theory of reference rapidly change in the Seventies (compare the quotations from Syntactic Structures with the others). From a theoretical point of view, it seems to me that the notions of entity, concept and representation need a serious work of clarification.

\section{Internalized reference, truth, and communication}

\subsection{Internalized reference and truth}

The Chomskian notion of internalized reference involves two different problems. The first one concerns the truth judgments of speakers, and can be summarized by this question: if the

assumptions: if reference was a purely causal relation, why must Twin Earthians and Earthians examine the liquids and associate to them a formula to distinguish them? Namely, if they had a causal relation with the local samples, this causal relation should permit to them to distinguish their samples from any other samples in every circumstance. The problem, in Fodor's theory, is represented by the notion of cause: "to say that symbols of the language of thought refer to what causes them, without specifying a context which may determine which causal connections are relevant, is to say nothing at all” (Casalegno 1997, ch. 13 cited in Marconi 1997: 104). Casalegno's objection can be appreciated considering that Fodor's relates the causal relation of reference to the chemical properties of the liquids: from a chemical point of view, all the samples on Twin Earth (and on Earth) are identical among them; but from another point of view (position, quantity, etc.), they are completely different. 
reference of expressions is internal and individual, how can speakers converge in their truth judgments? Of course, we are dealing with common truth judgments, namely with judgments concerning the truth of "simple" sentences, like The table is brown, John is running, etc. This problem has been pointed out by Casalegno (1997: 336):

\begin{abstract}
'it is unclear what must be thought, in Chomsky's perspective, about the notion of truth. As we know, according to the tradition, reference and truth are two inseparable notions. That single words have a reference is important to determine the truth values of the sentences in which they appear. If now we reinterpreted the notion of reference in an internalist perspective, as Chomsky would like, we should force to do the same with the notion of truth: we should, in other words, try to reduce the truth to a property of sentences which depends only on the internal structure $[\ldots]$ of the mental representations which correspond to the worlds. But it is hard to imagine such a property, and yet Chomsky does not offer any indication concerning this matter. On the other hand, if the connection between the notion of reference and that of truth failed, we could not state that the new [internalized] notion of reference "has many of the properties of the reference" (see Chomsky 1986: 44-45) intended in the traditional way, and we could not invoke the notion of reference to justify the practice of model-theoretic semantics.' (my translation)
\end{abstract}

Casalegno's words contains three different arguments. The first one: if we assume the internalized reference, and if truth and reference are inseparable (the truth depends on the reference), then it is necessary to provide an internalist interpretation of the truth; but this interpretation does not permit to explain the convergence of speakers in truth judgments. The second one: if the first argument is right, then the Chomskian notion of reference lacks "many of the properties of reference", as interpreted in the philosophical tradition. The third one: if the first and second arguments are right, then it follows that the notion of truth in model-theoretic semantics cannot be justified.

It is surprising that Casalegno considers these argument relevant for criticizing Chomsky's notion of reference. The second and the third arguments are, in fact, wrong: the aim of semantics is not to determine the truth values of a sentence; it is to express the truth conditions of a sentence. Model-theoretic semantics does not involve the notion of truth; it involves - and it expresses - the truth conditions of a sentence, judged in a specific model. So, even if we assume, as Casalegno does, that the truth depends on the reference, then this assumption is not a problem for model-theoretic semantics, which explains when - under which conditions - a sentence is true, not if it is true of false (see Dowty 1979, Bonomi 1983). As Marconi (1997: 107) pointed out, model-theoretic semantics is

'a theory of semantic effects of composition. What MT [model-theoretic] semantics says, the kind of information it provides, concerns how composition affects meaning: what the effect is of combining certain constituents in a certain way. In principle, MT semantics has nothing to say concerning the constituents' meaning; however, it has a lot to say concerning the semantic contribution of syntactic structure. MT semantics is functional semantics: the meaning of a linguistic expression is (expressed as) a specific function of ultimately unspecified constituents meanings. Alternatively, it could be presented as a theory of meaning for syntactic classes of linguistic expressions that does not distinguish among individual members of the same class.'

(Marconi 1997: 107)

The first argument - the relation between internalized reference and truth - has been discussed also by Wolfram Hinzen, in his Internalism About Truth, where the author 
proposes an argument which can be summarized the following way: assuming that the notion of truth as proposed in the externalist perspective is implausible, the only alternative is to interpret it in an internalist perspective, as Chomsky does, where the concept of truth, Hinzen explains, is not a material concept, but a formal or structural concept (see also Hinzen 2003), strictly connected with the mental representations and the meta-representations generated by the computational system. Assuming, following Fodor (1998), that there does not exist a theory for the concept of truth (such concept is in fact simply given, as any primitive concept), Hinzen wonders about how it is possible to justify the objectivity of reference namely, its realistic component in the sense of Dworkin (1996) and Nagel (1997) - inside Chomskian internalist approach. The author does not provide a solution, but he highlights that we must not think that an internalist version of truth corresponds to a subjective version of truth.

The author is right in pointing out that the internalist reference alone does not explain how speakers converge in their denotations, truth judgments, etc. However, it seems to me that Chomsky provides a sufficient answer to this problem, even if he does not deeply analyze it: he thinks in fact that denotation and reference are determined by many factors (beliefs, desires, etc.) which interact with the faculty of language and determine how speakers use the formal expressions generated by the grammar in their speech acts (see i.e. Chomsky 2000: 70 and ff.). However, no scientific theory can consider and study all these factors together, since "no one seeks to study everything" (Chomsky 2003: 290). This scepticism concerning a naturalistic account of the whole linguistic behavior pushed Chomsky to sustain that the most interesting approach for studying the linguistic behavior is that inaugurated by the philosophers of ordinary language (the later Wittgenstein, Austin, and many others) (see Chomsky 2005: 4). So, assuming the theoretical distinction between the (philosophical) notion of reference and the referential act (denomination, denotation, etc.), it is not clear why a supporter of Chomsky's perspective should justify the objectivity of reference; eventually, she must justify the converge of speakers in their referential acts, and Chomsky has never denied that psycholinguistics, cognitive science, etc. can tell us something about such matter.

\subsection{Is an internalist account to communication possible?}

I have said that, according to Chomsky, reference is determined by many factors which interacts with the faculty of language, and I have pointed out that this hypothesis can be used to explain the speakers' convergence in truth judgments and in referential acts, which represent a part of a major problem, that I can formulate this way: if the language is internal, individual and intensional - and the reference is - how can we explain the fact that through the language speakers can express their thoughts, command, ask, compose a poetry, etc.; namely, that they can communicate? This question has never particularly interested Chomsky, who has provided a brief answer that I will examine here. First of all, however, it must be reminded that, according to Chomsky, language did not emerge for communication. Chomsky does not agree with the adaptive hypothesis, according to which language developed for communicating: 
'The purpose of language is communication in much the same sense that the purpose of the hearth is pump blood. In both cases it is possible to study the structure independently of the function but pointless and perverse to do so, since structure and function so obviously interact. We communicate primarily with other people, but also with ourselves, as when we talk or think in words to ourselves.'

(Searle 1969: 80)

This hypothesis is rejected by Chomsky, who thinks instead that language emerged when the recursion principle was activated in the human mind (or in the brain). Recursion and discreteness are two biological isolated properties of the human species (Chomsky 2000: 52), and it is possible to assume that the emergence of language is the result of a sudden and rapid evolution of human brain: language, according to Chomsky (see i.e. 2001: 89-90), functions optimally (for a different hypothesis inside the generative perspective, see Pinker and Jackendoff 2005). As Chomsky (2000: 163) says,

'Informal discussion of evolutionary processes makes use of such locutions as "solving problems," but again that is not to be taken too seriously. Physical law provides narrow channels within which complex organisms may vary, and natural selection is doubtless a factor in determining the distribution of traits and properties within this constraint. $A$ factor, not the factor...'

Chomsky quotes what Darwin wrote in the Introduction of the last edition of The Origin of the Species:

'in the first edition of this work, and subsequently, I placed in a most conspicuous position - namely, at the close of the Introduction - the following words: "I am convinced that natural selection has been the main but not the exclusive means of modifications". This has been no avail.'

(1859, in Gould 1982: 45)

Furthermore, Chomsky argues that the idea summarized by Searle cannot be accepted because it is not easy to draw a relation between the structure of the faculty of language (the syntactic modulo) and the communication:

'When it can be shown that structures serve a particular function, that is a valuable discovery. To account for or somehow explain the structure of UG, or of particular grammars, on the basis of functional considerations is a pretty hopeless prospect, I would think; it is, perhaps, even "perverse" to assume otherwise.

... the need of locomotion influenced the humans developed legs and birds wing. This observation is not very helpful to the physiologist concerned with the nature of human body.'

(Chomsky 1975: 57-58)

Chomsky's "pop up" hypothesis has implausible consequences. For example, is it plausible to assume that language, as we know it, suddenly appeared in primates, namely that a primate suddenly began to play Sheakespeare's sonets (see Medawar 1957)? Another problem has been pointed out by Bates, Thal and Marchman (1991: 30-35), who have argued that if we deny that language is the result of an adaptive process, we can assume only two hypothesis: the divine creation or the Big Bang.

In The Language Instinct, Pinker defends the adaptive hypothesis from Chomsky's attack. He states that evolution must not be represented as a chain, but as bush, so that the creatures most similar to us, the chimpanzees, could be our cousins, and not our parents. 
Consequently, there have probably been many extinguished species whose members gradually developed the language. So, to assume that language is property unique to our species is like to assume that trunks are the unique property of elephants if no other animal on the Earth had the trunk. Pinker concludes that

\footnotetext{
'Natural selection is not just a scientifically respectable alternative to the divine creation. It is the only alternative that can explain the evolution of a complex organ [...]

[...] natural selection is the only process that can steer a lineage of organisms along the path in the astronomically vast space of possible bodies leading from a body [...] The alternatives to natural selection can, in contrast, only grope randomly.' (360-361)
}

Furthermore, as Lappin et al. (2000a, b, 2001) pointed out, there are not empirical reason to assume, as Chomsky does, that language is a system which functions perfectly.

On the Chomskian side, there are some scholars who tried to defend Chomsky's "pop up" hypothesis focusing on the advantages that the language would have led in the natural selection. Here is what Premack (1985: 281-282) wrote:

'I challenge the reader to reconstruct the scenario that would confer selective fitness on recursivness. Language evolved, it is conjectured, at a time where humans and protohumans were hunting mastodons [...] Would it be a great advantage for one of our ancestors squatting alongside the embers, to be able to remark: "Beware of the short beast whose front hoof Bob cracked when, having forgotten his own spear back at camp, he got in a glancing blow with the dull spear he borrowed from Jack"?

Human language is an embarrassment for evolutionary theory because it is vastly more powerful than one can account for in terms of selective fitness. A semantic language with simple mapping rules, of a kind one might suppose that the chimpanzee would have, appears to confer all the advantages that one normally associates with discussions of mastodons hunting or the like.'

Actually, the challenge is not hard. To be able to communicate has many advantages for the survival of a specie: communication allows the cooperation among the members of a group, and we can think that more and more complex messages can be generated by the recursion principle.

I do not want to focus any more on the debate concerning the evolution of language; I think that these few and inevitably incomplete quotations are useful to understand that Chomsky's "pop up" hypothesis is as plausible (and as implausible) than the adaptive hypothesis. Anyway, let me point out an objection against the adaptive hypothesis defended by Pinker and others: if the recursion principle is a consequence of an adaptive process, why do not humans use such principle in all its power? In other words, what is the reason why human beings have memory limitations which prevent them to construct longer sentences (perhaps, language could consist in a single, infinite sentence)? There is a discrepancy between the potentialities of recursion and the memory limitations of human mind: how can we justify this discrepancy in the adaptive hypothesis?

Coming back to the problem of communication in the internalist approach, let's analyze how Chomsky himself solved this problem. In the Sixties, Chomsky explained communication focusing on the notion of homogeneous speech-community. We read in Aspects: 
'Linguistic theory is concerned primarily with an ideal speaker-hearer in a completely homogeneous speechcommunity, who knows its language perfectly and is unaffected by such grammatically irrelevant conditions, as memory limitations, distractions, shifts of attention and interest, and errors (random or characteristic) in applying his knowledge of the language in actual performance.' (3)

Since Aspects, many scholars argued that it was not possible to postulate a (perfectly) homogeneous speech-community. The MIT linguist answered pointing out that those who rejected the notion of homogeneous speech-community were obliged to assume or that "people is so constituted that they would be incapable of learning language in a homogeneous speech community" or that "though people could learn language in a homogeneous speech community, the properties of the mind that make this achievement possible do not enter into normal language acquisition in the real world of diversity, conflicts of dialects, etc." (Chomsky 1980: 25-26; see also 1986: 17); however, both these conclusions are implausible. It is not clear how to judge the notion of homogeneous speech-community. Probably, it is adequate only when we look at the syntax of human language: if syntactic principles are "stored" in the faculty of language - so that they are innate - then it is plausible to say that they are perfectly shared by all the speakers (considering the activation of different parametres and the Saussurian arbitrariness of the lexicon). However, focusing on the shared syntactic principles is not sufficient to explain all the linguistic phenomena that are involved in the communication (semantic inferences processing, pragmatic principles, etc.).

The notion of homogeneous speech-community was rapidly abandoned by Chomsky. In Rules and Representations, the MIT linguist replaced the notion of language with the notion of grammar. Some years later, in chapter 2 of Knowledge of Language, Chomsky distinguishes between E-language and I-language, defined, respectively, as "a pairing of sentences and meanings [...] over an infinite range" (19-20) and "some element of the mind of the person who knows the language, acquired by the learner, and used by the speaker-hearer" (22). Fodor and Lepore (1992) argued that the notion of I-language entails that it is impossible to study communication between time slices of an idiolect. Chomsky (2000: 30) answered this way:

'These views are not well founded. Successful communication between Peter and Mary does not entail the existence of shared meanings or shared pronunciations in a public language (or a common treasure of thoughts or articulations of them), any more than physical resemblance between Peter and Mary entails the existence of a public form that they share.

[...] It may be that when he listens to Mary speak, Peter proceeds by assuming that she is identical to him, modulo M, some array of modifications that he must work out. Sometimes the task is easy, sometimes hard, sometimes hopeless. To work out M, Peter will use artifice available to him, thought much of the process is doubtless automatic and unreflected.'

During the linguistic interaction, Peter constructs a modulo $M$ assuming that Mary is enough similar to him; he will try, so, to construct an "adequate theory" for M: "insofar as Peter succeeds in these tasks, he understands what Mary says as being what he means by his comparable expressions" (see again Chomsky 2000: 30).

Graffi (1995) pointed out many relations between Chomsky's thought and Hermann Paul's one (see Paul 1910, 1920). As Graffi reminds, Paul (1920: 29) explained the communication focusing on the notion of linguistic average: according to Paul (1920: 15), the 
use of language determines a linguistic average drawn from the interaction between single linguistic organisms, and the mutual comprehension is possible because

\begin{abstract}
'Everything that we believe to know about the representation of another individual only rests on conclusions which have been drawn about our own. We further presuppose that the mind of the other is in the same relationship with the external world as our own mind, that the same physical impressions bring about in it the same representations as in our own, and that such representations connect with each other in the same way.' (Graffi's translation)
\end{abstract}

The constitutional uniformity of individuals (see Graffi 2001: 46) allows to understand Chomsky's thought, which can be summarized this way: the communication is possible because (1) there is a generative procedure (the faculty of language) that constructs syntactic structures and (2) human beings are constitutionally uniform, so that they can read other speakers' human behavior. This interpretation of Chomsky's thought is supported by what the MIT linguist says about Davidson's theory of language. According to Davidson (1986), "there is not such thing as a language, not if a language is anything like what many philosophers and linguists have supposed" (446): during every linguistic interaction, the speaker-hearer disposes of a "antecedent theory" which is modified during communication to produce a "transitory theory" (or "contingent"); however, it is not possible to define such theories by using the common notion of language. Communication consists in the ability of the speaker-hearer "to converge on a passing theory from time to time" (445). Consequently, according to Davidson, we must "abandon [...] not only the ordinary notion of language, but we have erased the boundary between knowing a language and knowing our way around the world generally [...] In linguistic communication, nothing corresponds to a linguistic competence" (445-446). Chomsky agrees with Davidson in arguing that the usual notion of language must be abandoned, but thinks that "no reason has been offered to doubt that there is a "prior theory" in the usual sense of the study of language and knowledge of language; that is, a specific generative procedure incorporated in a specific mature state of language faculty" (Chomsky 2000: 69), which corresponds, as Chomsky writes (70-73), to the I-language.

\title{
5. Conclusions
}

Let me highlight some problems which are relevant in this discussion and which do not find a solution in Chomsky's works. First of all, even if Chomsky's criticisms against the notion of externalized reference is plausible, Chomsky does not explain why such a notion - that of Bedeutung - is instead valid in the case of artificial and scientific languages: what is the difference between natural language and artificial-scientific languages? Perhaps, considering the quotations mentioned in Section 1, we could provide two answers, both of them in accordance with Chomsky's arguments: (1) the notion of Bedeutung is adequate for scientific languages because the symbols of these languages denote abstract entities; (2) the notion of Bedeutung is adequate for scientific languages because in these languages the reference is rigidly established through convention. I do not know the right answer, but I think that it could be an interesting topic of discussion. 
I have shown, I hope, that Chomsky's theory is immune from Casalegno and Hinzen's criticism; this does not mean, however, that Chomsky is clear in his arguments: it seems to me that to better understand Chomsky's thought it would be necessary to better define the ontology of the notions that Chomsky introduces, and their place in the generative grammar architecture. This work of conceptual clarification is necessary also to solve an important problem, namely the relation between syntax and semantics (and pragmatics) in generative grammar: how can model-theoretic semantics be interpreted in an internalist perspective? And, so, what is its role in generative grammar? These questions are crucial for the future of generative linguistics, especially if one considers the recent "semantic turn" of generative grammar (see i.e. Chomsky 2007, 2008).

\section{References}

Bates, E., D. Thal, and V. Marchman. 1991. In N.A. Krasnegor, D.M. Rumbaugh, R.L. Schefelbusch, M. StuddertKennedy (eds.), Biological and behavioral determinants of language development. Hillsdale: Erlbaum.

Bonomi, A. 1983. Linguistica e logica. In C. Segre (ed.), Intorno alla linguistica, 148-171. Milano: Feltrinelli. Borghi, A.M. 2010. Comprensione del linguaggio: Movimento, azione, socialità. Teorie \& Modelli XVI: 67-76.

Borghi, A.M., and F. Cimatti. 2009. Words as tools and the problem of abstract words meanings. Proceedings of the 31st Annual Conference of Cognitive Science Society: 2304-2309. Amsterdam: Cognitive Science Society.

Borghi, A.M., and F. Cimatti. 2010. Embodied cognition and beyond: Acting and sensing the body. Neuropsychologia 48: 763-773.

Casalegno, P. 1997. Filosofia del linguaggio. Firenze: La Nuova Italia Scientifica.

Chomsky, N. 1955. Logical Syntax and Semantics. Their Linguistic Relevance. Language 31(1): 36-45.

Chomsky, N. 1957. Syntactic Structures. The Hague: Mouton.

Chomsky, N. 1964. Current Issues in Linguistic Theory. The Hague: Mouton.

Chomsky, N. 1975. Reflections on Language. New York: Pantheom.

Chomsky, N. 1976. Conditions on Rules of Grammar. Linguistic Analysis 2: 303-351.

Chomsky, N. 1977. On wh-Movement. In P.W. Culicover, T. Wasow, and A. Akmajian (eds.), Formal Syntax, $71-$ 132. New York-San Francisco-London: Academic Press.

Chomsky, N. 1980. Rules and Representation. New York: Columbia University Press.

Chomsky, N. 1981. Lectures on Government and Binding. Dordrecht: Foris.

Chomsky, N. 1986.. Knowledge of Language. Its Nature, Origin and Use. Praeger.

Chomsky, N. 2000. New Horizons in the Study of Language and Mind. Cambridge MA: The MIT Press.

Chomsky, N. 2001. On Nature and Language. Siena: Università degli Studi di Siena.

Chomsky, N. 2005. Three Factors of Language Design. Linguistic Inquiry 36(1): 1-22.

Chomsky, N. 2012. The Science of Language and Mind. Interviews with James McGilvray. Cambridge MA: Cambridge University Press.

Davidson, D. 1986. A Nice Derangement of Epitaphs. In E. Lepore (ed.), Truth and Interpretation, 307-319. Oxford: Blackwell.

Davidson, D. 1991a. Epistemology Externalized. Dialectica XLV: 191-202.

Davidson, D. 1991b. Three Varieties of Knowledge. In A. Phillips Griffiths, A.J. Ayer (eds.), Memorial Essays, 153-166. Cambridge, MA: Cambridge University Press.

Delfitto, D., and G. Graffi. 2005. Chomsky fra storia della scienza e filosofia del linguaggio. In N. Chomsky. 2000, trad. it. Nuovi orizzonti nello studio del linguaggio e della mente, 9-33. Milano: Il Saggiatore.

Darwin, C. 1857/1968. The Origin of Species by Means of Natural Selection. Edited by J.W. Burrow. Harmondsworth: Penguin.

Dworkin, R. 1996. Objectivity and Truth: You'd Better Believe It. Philosophy and Public Affairs 25(2): 87-139. 
Dowty, D. 1979. Word meaning and Montague Grammar: the semantics of verb and time in generative semantics and in Montague PTQ. Dordrecht: Reidel.

Fodor, J.A. 1975. The Language of Thought. Hassocks: Harvester.

Fodor, J.A. 1998. Concepts: Where Cognitive Sciences Went Wrong. New York: Oxford University Press.

Fodor, J.A., and E. Lepore. 1992. Holism: A Shopper's Guide. Oxford: Blackwell.

Goodman, N. 1949. On likeness of meaning. Analysis 10(1): 1-7.

Goodman, N. 1953. On some differences about meaning. Analysis 13(4): 90-96.

Gould, S.J. 1982. The Panda's Thumb. New York: Norton.

Graffi, G. 1975. Equivalenti o inconciliabili? Su alcuni sviluppi recenti della linguistica trasformazionale. In U. Vignuzzi (ed.), Teoria e storia degli studi linguistici. Atti del VII Convegno della Società Italiana di Linguistica, Roma 2-3 giugno 1973, 2, 281-338. Roma: Bulzoni.

Hart, J., and G. Gordon. 1992. Neural Subsystems for Object Knowledge. Nature 359: 60-64.

Hinzen, W. 2003. Truth's Fabric. Mind and Language 18(2): 194-219.

Hinzen, W. 2006. Internalism About Truth. Mind and Society, 5(2): 139-166.

Katz, J.J., and J. Fodor. 1963. The Structure of a Semantic Theory. Language 39: 170-210.

Kay, M.J., and A. Ellis. 1987. A Cognitive Neuropsychological Case Study of Anomia. Brain 110: 613-629.

Kripke, S.A. 1972. Naming and Necessity. In G. Garman, and D. Davidson (eds.), Semantics of Natural Language. Dordrecht: Reidel.

Kripke, S.A. 1980. Naming and Necessity. Cambridge, MA: Harvard University Press.

Lappin, S., R.D. Levine, and D.E. Johnson. 2000a. The Structure of Unscientific Revolutions. Natural Language and Linguistic Theory 18: 665-771.

Lappin, S., R.D. Levine, and D.E. Johnson. 2000b. The Revolution Confused: A Reply to our Critics. Natural Language and Linguistic Theory 18: 873-890.

Lappin, S., R.D. Levine, and D.E. Johnson. 2001. The Revolution Maximally Confused. Natural Language and Linguistic Theory 19: 901-919.

Marconi, D. 1997. Lexical Competence. Cambridge, MA: The MIT Press.

Medawar, P.B. 1957. An unsolved problem in biology. In P.B. Medawar (ed.), The uniqueness of the individual. London: Methuen.

Meini, C., and A. Paternoster. 1992. Understanding Language Through Vision. In P. McKevitt (ed.), Integration of natural language and Vision Processing, 3, Computational Models and Systems. Dordrecht: Kluwer.

Miceli, G., L. Giustolisi, and A. Caramazza. 1991. The Interaction of Lexical and Non-Lexical Processing Mechanisms: Evidence from Anomia. Cortex 27: 57-80.

Nagel, T. 1997. The Last Word. New York and Oxford: Oxford University Press.

Paul, H. 1910. Ueber Volkerpsychologie. Suddeutsche Monatshefte 10: 363-373.

Paul, H. 1920. Prinzipien der Sprachgesschichte. Halle: Niemeyer.

Piattelli-Palmarini, M. 1986. The Rise of Selective Theories: A Case Study and Some Lessons from Immunology. In W. Demopolous, and A. Marras (eds.), Language Learning and Concept Acquisition: Foundational Issues, 117-130. Norwood, N.J.: Ablex.

Pinker, S. 1994. The Language Instinct. New York: Harper Perennial Modern Classics.

Pinker, S., and R. Jackendoff. 2005. The Faculty of Language: What's Special About It? Cognition 95: 201-236.

Premack, D. 1985. Gavagai! or the future history of animal language controversy. Cambridge, MA: The MIT Press. Prinz, J.J. 2002. Furnishing the Mind. Concepts and Their Perceptual Basis. Cambridge, MA: The MIT Press.

Putnam, H. 1975. The Meaning of 'Meaning'. In H. Putnam (ed.), Philosophical Papers, 2, Mind, Language and Reality, 215-271. Cambridge, MA: Cambridge University Press.

Putnam, H. 1986a. Meaning Holism. In L.E. Hahn, and P.A. Schilpp (eds.), The Philosophy of W.V.O. Quine, 405426. Open Court: La Salle.

Putnam, H. 1986b. Meaning in Our Mental Life. In E. Ullmann-Margalit (ed.), The Kaleidoscope of Science, 17-32. Dordrecht: Reidel.

Putnam, H. 1988. Representation and Reality. Cambridge, MA: The MIT Press.

Putnam, H. 1992. Replies. Philosophical Topics 20: 347-408.

Quine, W.V.O. 1951. Two Dogmans of Empiricism. The Philosophical Review 60: 20-43. 
Rizzi, L. 1978. Chomsky e la semantica. Studi di grammatica italiana 7: 161-182. Firenze: Accademia della Crusca Edizioni.

Reuland, E. 2001. Primitives of Binding. Linguistic Inquiry 32(3): 439-492.

Riddoch, M.J., and G.W. Humphreys. 1987. Visual Object Processing in Optic Aphasia: A Case of Semantics Access Agnosia. Cognitive Neuropsychology 4: 131-185.

Rosenfeld, A. 1988. Computer Vision. Advances in Computers 27: 265-308.

Searle, J.R. 1969. Speech Acts. London: Cambridge University Press.

Shallice, T. 1988. From Neuropsychology to Mental Structure. Cambridge, MA: Cambridge University Press.

Tye, M. 1991. The Imagery Debate. Cambridge, MA: Cambridge University Press.

Voltolini, A. 2001. Why the Computational Account of Rule-Following Cannot Rule Out the Grammatical Account. European Journal of Philosophy 9(1): 82-105.

Warrington, E.K. 1985. Agnosia: The Impairment of Object Recognition. In J.A.M. Frederiks (ed.), Clinical Neuropsychology, Handbook of Clinical Neurology, 333-349. Amsterdam: Elsevier Science Publishers.

Weinreich, U. 1966. Explorations in Semantic Theory. In T.A. Sebeok (ed.), Current Issues in Linguistics, 3, 395798. The Hague: Mouton. 